\title{
An Interesting Case of Basal Cell Carcinoma with Raynaud's Phenomenon Following Chronic Arsenic Exposure
}

\author{
Shazia Gulshan, ${ }^{1}$ Mohammad Jawaid Rahman, ${ }^{2}$ Ranu Sarkar, ${ }^{1}$ Suman Ghosh, ${ }^{1}$ Rathin Hazra' \\ 'Department of Pathology, NRS Medical College, Kolkata, India, ${ }^{2}$ Department of Urology, Regional Institute of Medical \\ sciences, Imphal, India.
}

\section{ABSTRACT}

Arsenic is commonly known to be associated with squamous cell carcinoma. Among the lesser known associations is basal cell carcinoma and even rarer is its effect on blood vessels causing peripheral vascular disease. Here we present a case of a $55 \mathrm{yr}$ old man with ulceroproliferative lesions on scalp and forehead along with several hyperpigmented patches on trunk and extremities. He had symptoms suggestive of Raynaud's phenomenon that eventually led to digital gangrene. FNAC was done which was suggestive of basal cell carcinoma. On further enquiry, he was found to reside in an arsenic endemic zone and was investigated for blood arsenic level which was elevated. Punch biopsy from different lesions from body confirmed nodular basal cell carcinoma. Presently the patient has stopped drinking water from the local tubewell. On follow-up he shows improvement of Raynaud's phenomenon and skin lesions.

Keywords: basal cell carcinoma; chronic arsenic exposure; raynaud's phenomenon.

\section{INTRODUCTION}

Chronic arsenic exposure is seen to be commonly associated with squamous cell carcinoma. Basal cell carcinoma following arsenic exposure is seen to occur to a lesser extent and even rarer is its effect on blood vessels leading to peripheral vascular disease. Cases have been reported along the coastal region of Taiwan but it is very uncommon in India and elsewhere worldwide. We do hereby present this case because of the rare association of basal cell carcinoma with arsenic exposure and Raynaud's phenomenon. ${ }^{1-4}$ Increase in awareness of people living in endemic zones can stop disease progression.

\section{CASE REPORT}

A $55 \mathrm{yr}$ old male with an ulceroproliferative growth on scalp increasing in size for $10 \mathrm{yrs}$ and a pigmented lesion for 7 yrs along with several hyperpigmented patches on trunk and extremities. He had symptoms suggestive of Raynaud's phenomenon resulting in digital gangrene. FNAC was suggestive of basal cell carcinoma. On further enquiry, he was found to reside in an arsenic endemic zone drinking water from local tube wells. His blood arsenic level was elevated. Punch biopsy done from different lesions confirmed nodular basal cell carcinoma. He underwent excision of the scalp lesion (Figure 1, 2).
Correspondence: Dr. Shazia Gulshan, Department of Pathology, NRS Medical College, Kolkata, India. Email: shzgulshan@gmail.com, Phone: +919007790139 . 

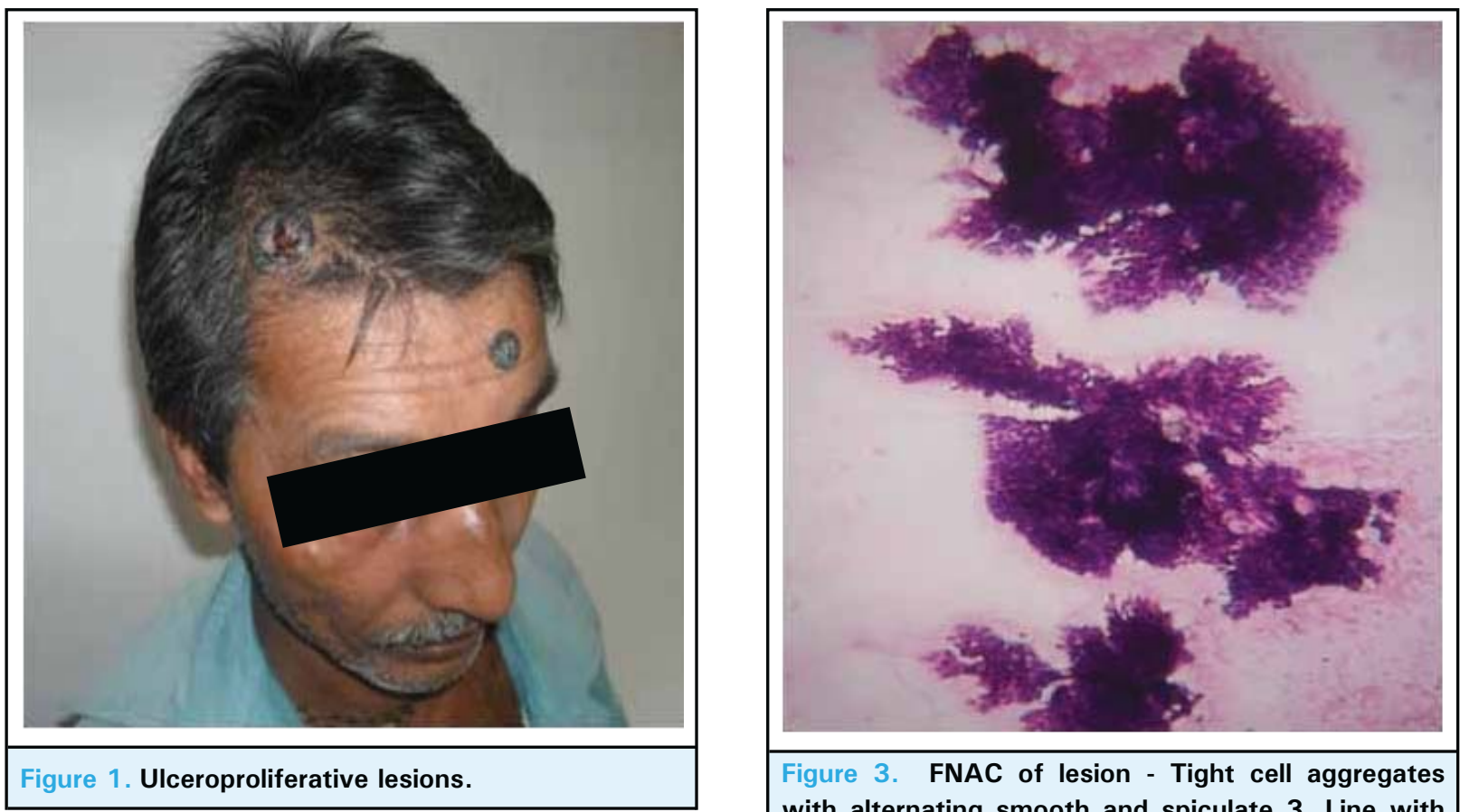

Figure 3. FNAC of lesion - Tight cell aggregates with alternating smooth and spiculate 3 . Line with palisading of nuclei along the edge of the aggregates.
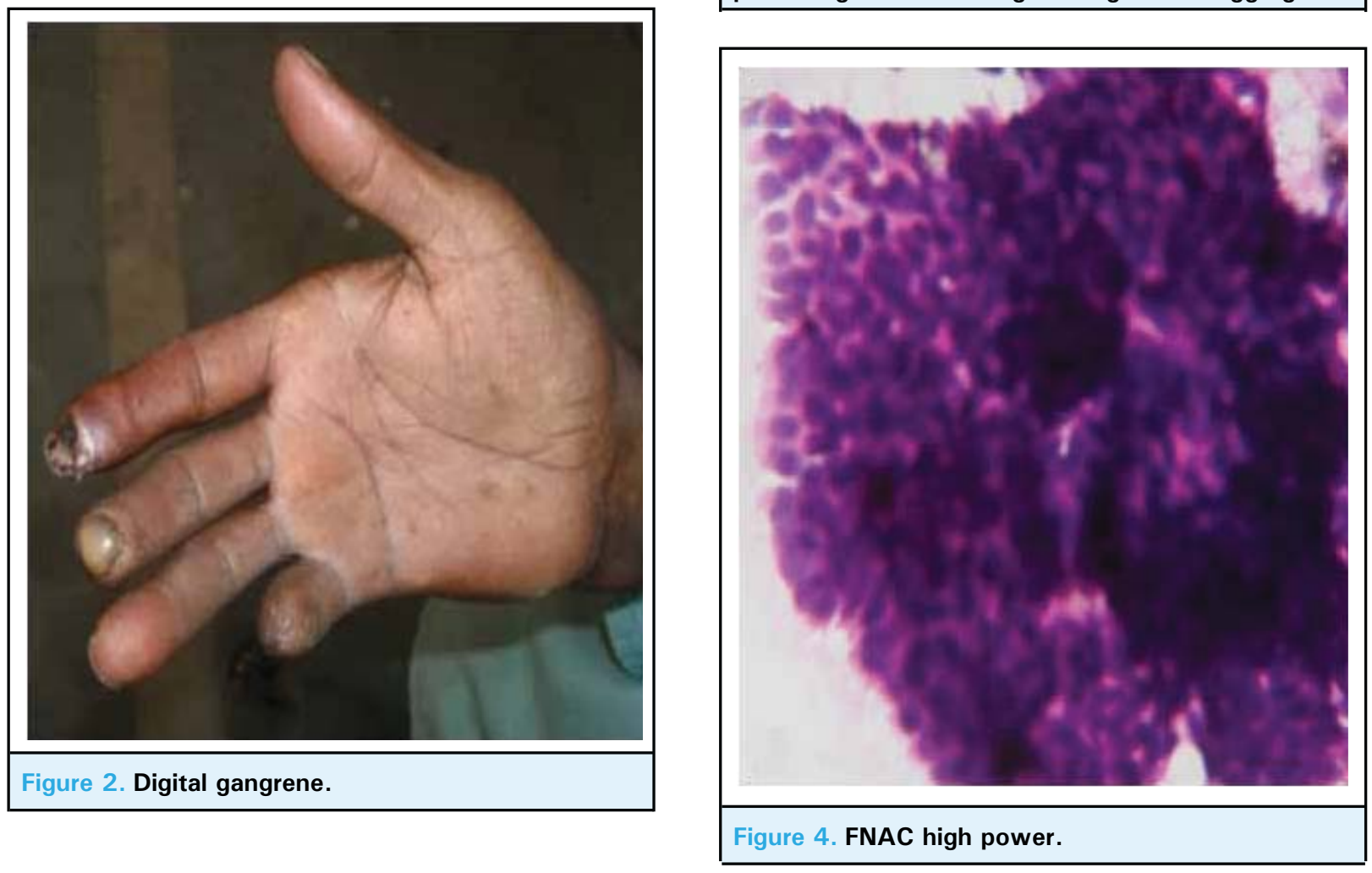


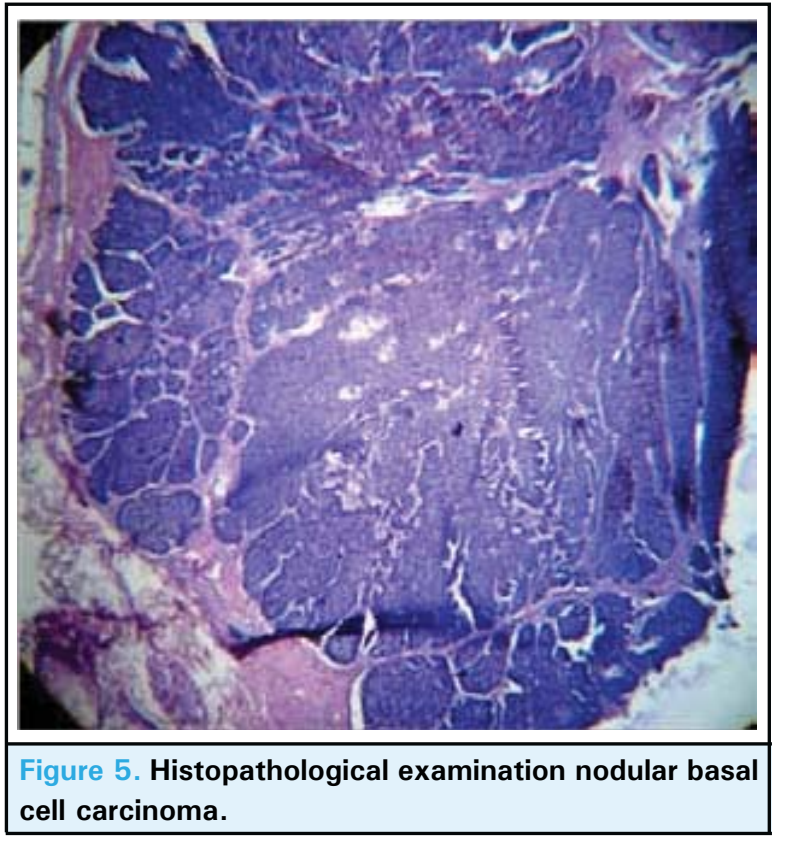

Follow up: Patient refrained from drinking water of local tube well. Instead he consumed from municipality water supply. Subsequently his skin lesions improved without any further progression. The symptoms of Raynaud's phenomenon also showed significant improvement. The FNAC in low power (100x) showed tight cell aggregates with alternating smooth and speculate line. Palisading of nuclei along the edge of the aggregates. In high power (400x) showed scanty cytoplasm and indistinct cell borders Small hyperchromatic ovoid nuclei and indistinct nucleoli. Variable stromal material. Whereas in H/P examination showed nodular Basal cell carcinoma (Figure 3-5).

\section{DISCUSSION}

Chronic arsenic poisoning is most commonly due to ingestion and has been well documented to be associated with cancers of the skin, lung, bladder, kidney and liver. Arsenic tends to accumulate in the skin. The most likely process of carcinogenesis is oxidative stress, chromosomal abnormality and altered growth factors. It is associated with $\mathrm{G} 2 \mathrm{M} /$ cell cycle arrest and DNA aneuploidy. ${ }^{1}$ The most common skin cancers associated with arsenic are Bowen's disease, squamous cell carcinoma and superficial basal cell carcinoma. Arsenic keratosis of palms and soles are a common premalignant manifestation. In a follow up study of patients taking Fowler's solution arsenic keratosis was seen in $40 \%$ and cancers in $8 \%$. In another study from Taiwan $80 \%$ of the patients had arsenical keratosis. ${ }^{5}$ Squamous cell carcinoma appears to be more commonly associated with chronic arsenic exposure than basal cell carcinoma. In one study SCC was seen in $25 \%$ of cases and BCC in $13.5 \%$ cases. $^{2,3}$ Peripheral vascular disease is among the lesser known of its effects. Several studies in Taiwan has revealed that Blackfoot disease, which involves the blood vessels of the legs is related to chronic arsenic exposure is found in people along the south-west coast of Taiwan. ${ }^{1}$

\section{Conflict of Interest: None.}

\section{REFERENCES}

1. Yu HS, Liao WT, Chai CY. Arsenic carcinogenesis in the skin. J Biomed Sci. 2006 Sep; 13(5):657-66.

2. Wong SS, Tan KC, Goh CL. Cutaneous manifestations of chronic arsenicism: review of seventeen cases. J Am Acad Dermatol. 1998 Feb;38(2):179-85.

3. Centeno JA et al. pathology related to chronic arsenic exposure. Environ Health Perspect. 2002 Oct; 110(Suppl 5): 883-6.
4. Shun-Long Chen, Kong-Hwa Chlu. Arsenic Species in Groundwaters of the Blackfoot Disease Area, Taiwan. Environ. sci. Technol. 1994(28):877-81.

5. Elder, David E. Lever's histopathology of the skin. Philadelphia: Wolters Kluwer Health; 2015. 